\title{
Spatiotemporal Dynamics of Ecological Variation Affect an Endangered Migratory Bird Black-faced Spoonbill (Platalea minor) in Southwestern Coast of Taiwan
}

\author{
Kun-Neng Chen \\ Department of Electrical Engineering, Kun-Shan University, Tainan, Taiwan \\ Email: knchen@mail.ksu.edu.tw
}

Received 25 December 2013; revised 23 January 2014; accepted 1 February 2014

Copyright (C) 2014 by author and Scientific Research Publishing Inc.

This work is licensed under the Creative Commons Attribution International License (CC BY). http://creativecommons.org/licenses/by/4.0/

\section{Open Access}

\begin{abstract}
Zengwun estuary in Taiwan is a key habitat for the endangered black-faced spoonbill (Platalea minor), a piscivorous migratory bird. In the winters 2011-2012 and 2012-2013, the percentages were nearly half of that in $2007-2008(65.5 \%$ and $51.1 \%)$. To find the reasons of the decline of the habitats is important for the preservation of the endangered bird. So, we used an unsupervised classification method to analyze high spatiotemporal satellite images from FORMOSAT-2 from 2004 to 2013, and found that the quality of spoonbill habitats has deteriorated. The deterioration mainly caused by many of the fishponds there, changing the raised fish from milkfish to grouper fish for the purpose of business benefit in recent 3 years. The water depth in the fishponds, which raised milkfish, used to be kept below $30 \mathrm{~cm}$ for the convenience in harvesting in winter. Besides, they left the uneconomical small fish behind in the ponds, which provided the black-faced spoonbills good places to forage. However, after the fishponds were changed to raise grouper fish, it not only made the small fish no more exist in the ponds, but also the developing engineering to deepen the fishponds made the trees around these ponds been cleaned. These trees could have provided shields for the black-faced spoonbills against chilly wind. As a consequence, these changes have substantially reduced the agreeable region where the depth of water should be less than $30 \mathrm{~cm}$ for black-faced spoonbill to forage and inhabit. New reserves for spoonbills have been established recently in Taiwan. Nevertheless, a detailed plan for maintaining food resources for spoonbills as well as returning them habitats, must be implemented immediately.
\end{abstract}

\section{Keywords}

Black-faced Spoonbill; Coastal Erosion; High Spatiotemporal Imagery; Taiwan 


\section{Introduction}

Evidence shows that climate change, road networks, disturbance, and coastal wetland quality affect species distribution and abundance [1]-[3]. The black-faced spoonbill (Platalea minor) is an endangered migratory bird endemic to East Asia [4]. Every winter, black-faced spoonbills migrate southward from North Korea, South Korea, and Liaodong Peninsula of China to Japan, Taiwan, Vietnam, Hong Kong, and Southeastern China [5] [6]. The southwestern coast of Taiwan, mainly Zengwun estuary, is a pivotal habitat for black-faced spoonbills because nearly half of black-faced spoonbills in the world come to Taiwan every year [7]-[9]. Though the number of black-faced spoonbill in total has increased in trend within two decades, the record of population in 2011 revealed a 22\% drop, particularly in the main wintering areas of Taiwan, with a decrease of 34\% [4] [10]. The decrease in number in Taiwan was much more than that of the world. Does it mean that the environment of the black-faced spoonbill's habitats in Taiwan has been substantially changed? In this research, we will talk about the reasons and also suggest some strategies for the protection of the spoonbill's habitats in Taiwan.

\subsection{Coastline Retreat}

Xinfulun sandbar in the north bank of Zengwen estuary is a rising, sediment, and erosion coast formed in recent 400 years. It heaps along the coast to form series of sandbars and lagoons, and become a rich fishery habitat [11] [12]. The land rising and sediment accumulating along coasts are considered to enrich the seabed terrain and the organic matter, thus being suitable for a diverse fish to spawn and forming an abounding ecosystem.

Zengwun Reservoir was constructed on Dapu River, the main branch of Zengwun River, between July 1967 and October 1973. After the reservoir was completed, the sediment flowing into Zengwun estuary fell from 14.8 million tons/year to 9.1 million tons/year [13]. Because sediments accumulated in the reservoir, deficient sand failed to replenish the estuary offsetting the slow loss of the sea sand and the erosion of the coast, which has made the coastline retreat farther back every year [14]. Building a dam across a river deprived of fine sediments in the river and exposes the gravel on the riverbed, not only accelerating bank erosion but also depleting estuarine sediments, which changes the coastal terrain and erodes the estuary coastline [15] [16].

Terrain changes in Zengwun estuary affect not only the estuary's aquatic ecology directly, but also the food resource and the roosting behavior of black-faced spoonbills indirectly [17] [18]. In recent years, sandbar and coastal erosion in Zengwun estuary have worsened because of several reasons: the reduction in river-sediment transportation, the construction of artificial structures along shores, land reclamation through pumping sand near the shore, extreme climate, land subsidence, and rising sea levels.

\subsection{Foraging Habitats and Satellite Imagery}

According to the research of our team, the large-scale mullet (Chelon macrolepis) is one of the main foods of the black-faced spoonbills [17]. The mullets, which are the dominant fish species, come to Zengwun estuary every winter to feed and breed. The large number of mullets attracted the black-faced spoonbills to foraging in Zengwun estuary every winter [12] [17] [18]. On the other hand, in the salt marshes along the southwestern coast in Taiwan, fishes including tilapias (Oreochromis hybrid), mosquito-fish (Gambusia affinis), sailfin molly (Poecilia velifera), and gobies (Gobiidae) have adapted to the brackish water. With water depths in these marshes below $30 \mathrm{~cm}$, these fishes are also another food resources for black-faced spoonbills [17].

Furthermore, around Zengwun estuary, most of fishponds used to raise milkfishes (Chanos chanos) and clams (Meretrix lusoria and Cyclina sinesis) [19]. When these fishponds are harvested every winter, the fishermen used nets with big mesh to leave uneconomical small fish behind in the fishponds, and reserved about $10 \mathrm{~cm}$ of water depth to let these trash fish for birds to avoid diseases caused by dead fish. In winter, they continually harvest milkfish fishponds, which provide a good food source for black-faced spoonbill. Moreover, the amount in total and in species of fish in Zengwun estuary also peaks in winter. All these provided rich food for the black-faced spoonbills. Because of these foraging resources, the area around Zengwun estuary has become a key habitat for the black-faced spoonbills.

In 1991, less than 200 black-faced spoonbills stayed in Taiwan during winter, but after endeavors on protection for 20 years, the number has increased 8-fold, and hence the food sources required for the birds increased as well. However, if there were deficient food sources and habitats in Zengwun estuary area, including the large area of harvested fishponds with shallow water in winter around there, some of the black-faced spoonbills would 
naturally move to other more productive habitats [8].

To understand the impact of the changes of fishponds and coastal terrain on the black-faced spoonbills, our study area covered the southwestern coast of Taiwan where the black-faced spoonbill stayed, including Aogu and Budai in Chayi County; Beimen, Cigu, and Sihcao in Tainan City; and Jiading in Kaohsiung City (Figure 1) [20].

Remote sensing, landscape, and geographical information systems have been used previously to study the effects of artificial disturbance on water birds [21]-[23]. In this research, we used spatiotemporal imagery from FORMOSAT-2 from 2004 to 2013 to analyze the terrain changes along Taiwan's southwestern coast, including Budai Salt Pan, Black-faced Spoonbills Refuge (BFSR) on the northern shore of Zengwun estuary, and the ecological corridors of black-faced spoonbills (Figure 1). We also presented proposals to help conserve the blackfaced spoonbills in the conclusions.

\section{Materials and Methods}

\subsection{Study Area}

The study area in our research, along the southwestern coast of Taiwan, extended north to Beigang River and south to Singda Harbor, with a north-to-south distance of $80 \mathrm{~km}$, and an east-to-west distance of $10 \mathrm{~km}$. We focused our study on salt marshes in estuaries, sandbars, lagoons, abandoned salt pans, and fishponds. Based on the behavior of black-faced spoonbills, moving between foraging and resting places, the population of these birds has been divided into 3 parts that occupy the following regions [21]: one, the Budai-Beimen wetlands, including Beigang, Bazhang, and Jishui estuaries; two, the Zengwen estuary, including Cigu Salt Pan, BFSR, sandbars, and nearby fishponds; and three, the Sihcao wetlands, including Sihcao Wildlife Refuge, nearby fishponds, and Jaiding Wetland (Figure 1).

We divided our study sites in the north shore of Zengwun estuary into 3 sites: BFSR, the intertidal zone of Xinfulun sandbar (IZXS), and Major Wildlife Habitat (MWH) (Figure 2). We also divided Budai Salt Pan Wetland into 4 sites, named Budai Lagoon (BL), South Budai Salt Pan (SBSP), North Budai Salt Pan (NBSP), and

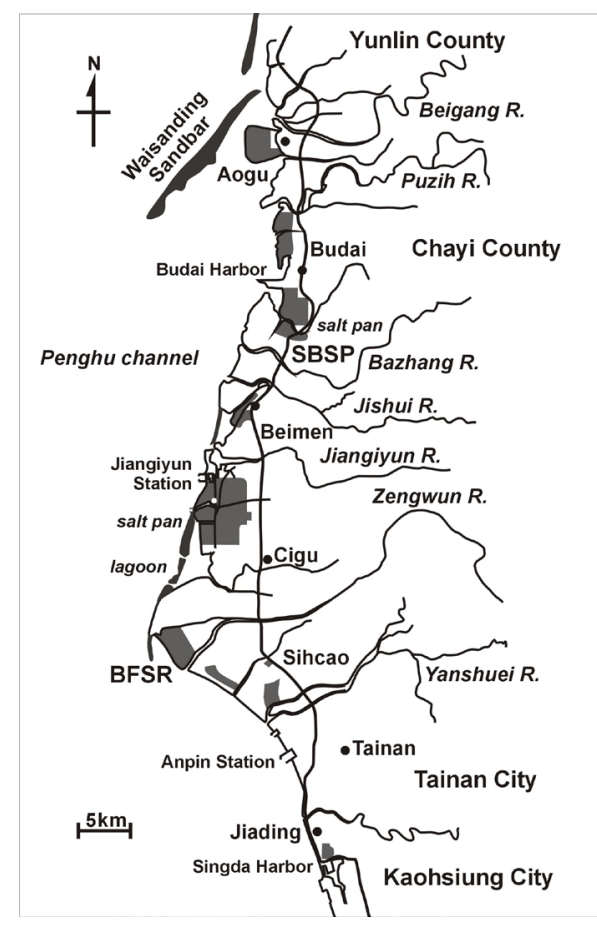

Figure 1. Studied area along the southwestern coast of Taiwan. BFSR: Black-faced Spoonbills Refuge, SBSP: South Budai Salt Pan, and R.: River. 


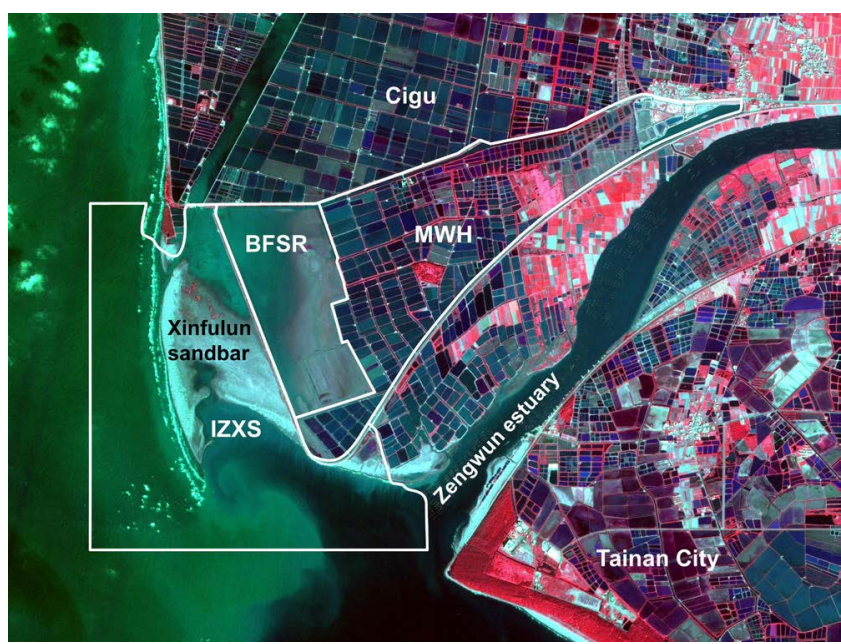

Figure 2. Studied sites on the north shore of Zengwun estuary in Tainan City. IZXS: intertidal zone of Xinfulun sandbar, BFSR: Black-faced Spoonbills Refuge, and MWH: Major Wildlife Habitat (composed of fishponds).

Budai Wetland Park (BWP) (Figure 3).

IZXS site was not only inhabited by crabs (including Scopimera bitympana, Scopimera longidactyla, Mictyris brevidactylus, Ocypode ceratophthalmus, and Ocypode sinensis) but also attracted fishermen who came to catch glass eels. Reference [24] further pointed out a total 81,818 fry specimens, belonging to 14 orders and 42 families, were collected in IZXS from April 2006 to April 2008. BFSR site was composed of the lagoons and the cofferdams around. There were 3 water gates in BFSR to connect Zengwun river and the sea, and the tide range was about $50 \mathrm{~cm}$. In the wintering period, the black-faced spoonbill came back BFSR to rest after foraging; sometimes, when the cold current came, they also foraged in BFSR. MWH site was composed of fishponds, which provided a large amount of trash fish for the black-faced spoonbill and the other egret after the fishponds being harvested continually in winter. But in recent 3 years, the raised fish in most of the fishponds were changed from milkfish to grouper fish or young milkfish (young milkfish was used as the bait for the angler). This change not only made that there no trash fish left for the birds, but also made the harvest time discord with the wintering period of the black-faced spoonbill.

Beside food sources, offering sufficient resting area for the black-faced spoonbill was important too. In recent 2 years, the number of the black-faced spoonbill decreased in the north shore of Zengwun estuary, and increased in Budai Salt Pan Wetland oppositely. From 1987 to 2003, land subsidence was approximately $124 \mathrm{~cm}$ in Budai Salt Pan Wetland that made more areas to be immerged in the water. Furthermore, the floodgates of the salt pan were opened slightly in winter to maintain the water at a low level. Both of the two measures increased the area of shallow water, which was suitable for the black-faced spoonbill's resting and foraging habits. Moreover, in 2011, a fence was built in NBSP to prevent the birds from being disturbed by people and dogs, thus providing a good new habitat for black-faced spoonbills. To compare the habitat qualities, for example the water depth and the building of the fence, before and after the change of the number of black-faced spoonbills and to study their foraging and resting behaviors would be helpful to understand the factors for the population change of them.

\subsection{Black-faced Spoonbill Population and Behavior}

From 2007 to 2013, Wild Bird Society of Tainan conducted field studies to record the number of black-faced spoonbills in wetlands along the southwestern coast of Taiwan; the number of birds were recorded once every 2 weeks during the black-faced spoonbill wintering period, from October to April. In the spring of recent 3 years, the black-faced spoonbills, stayed in Budai wetland, flied back and forth between Bazhang estuary and the nearby fishponds, and we tried to observe and analyze their needs for different habitats. During April and May of 2013, we observed the black-faced spoonbills in the sandbars in Bazhang estuary from 6:00 am to 7:00 pm once a week to record how they used the habitat. Once every $10 \mathrm{~min}$, we recorded spoonbill activities such as 


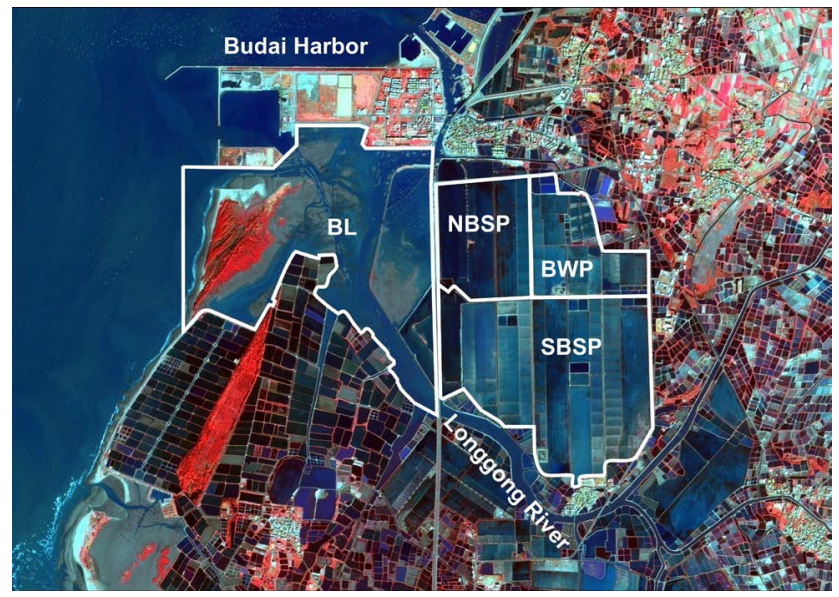

Figure 3. Studied sites of Budai Salt Pan Wetland in Chayi County. BL: Budai Lagoon, BSP: Budai Salt Pan (abandoned salt pans), and BWP: Budai Wetland Park.

foraging, resting, pluming, and movement in Bazhang estuary.

\subsection{Potential Prey Items of Black-faced Spoonbills}

From 2011 to the spring of 2013, we found that more black-faced spoonbills stayed in Bazhang estuary to rest than before, and some of them had foraging activities. To find their needs, we also studied the fish in the estuary to find if there existed the food source described in [17]. We used 5 large fyke nets and hoop-nets as described by [12] [17] to collect fish in Bazhang estuary every month from 2013 April 27 to 2013 June 23. The collected fish were sorted into the lowest taxonomic level possible using keys published by [25] [26], and total fish in each species were counted.

\subsection{Source of Satellite Images}

From the image collection at the Center for Space and Remote Sensing Research, National Central University, Taiwan, we selected 10 satellite images from satellite FORMOSAT-2 from 2004 to 2013; all selected photographs were taken at 9:00 am $( \pm 10 \mathrm{~min})$ and mostly during high tide or low tide. Among the 10 images, 3 were taken at high tide (9 December 2004, 31 January 2007, and 4 February 2012), when the water level was approximately $50 \mathrm{~cm}$ above sea level; and 3 were taken at low tide (5 February 2006, 3 January 2009, and 9 February 2011), when the water level was $20 \mathrm{~cm}$ below sea level. For comparison, we analyzed 2 additional satellite images of the Budai-Beimen wetlands (21 September 2012 and 29 April 2013) to estimate changes in water depths in the black-faced spoonbill's habitats.

\subsection{Unsupervised Classification}

Because water levels are dynamic along coasts, water depths in our study sites changed with tides. For our study, we used tidal information mainly from the Jiangiyun and Anpin stations of the Central Weather Bureau (Figure 1). One main purpose of this study was to estimate the impact water depth has on black-faced spoonbill within our study site. We used ENVI 4.8 software to classify the water depths and land topography from satellite images through unsupervised classification. The results of the classification were adjusted and confirmed by field surveys. We defined the range of water depth into 4 classes, wet ground, $0-0.3 \mathrm{~m}, 0.3-1.8 \mathrm{~m}$, and above $1.8 \mathrm{~m}$ to correspond to their potential usage by the black-faced spoonbills and the fishermen.

The black-faced spoonbill foraged in the intertidal and the harvested fishponds, but their resting area could be divided into two kinds: one was the open fields with sunshine, and the others were the downwind side of the clay-banks, mangroves, and shrubs to block the chilly north wind when cold current came. The vegetation was also an important factor for their staying. In the recognition of satellite images, the vegetation on land was divided into 4 types: dense, mid-dense, moderate, and sparse. After adding dry ground or road, dry sand or build- 
ing, and the 4 types of water depth, there were 10 classes in total.

\section{Results}

\subsection{Population Variance of Black-faced Spoonbills in Southwest Taiwan}

We found that more than $80 \%$ of the entire population of black-faced spoonbills in Taiwan stayed at the north shore of Zengwun estuary in early winter (October to December) from 2007 to 2010, and their numbers decreased gradually after this period (Figure 4). In the past 2 years (October 2011 to April 2013), the majority of black-faced spoonbills did not first come to Zengwun estuary in early winter, and those that came and stayed left early for other nearby habitats. The worst situation were in November of 2011 and 2012, when only $76 \%$ and 62\% of the whole spoonbills population of Taiwan stayed in Zengwun estuary and the other birds spread to wetlands such as Budai Salt Pan Wetland, Sihcao Wetland, and Jiading Wetland (Figure 4).

In April and May of 2013, only 6 black-faced spoonbills stayed in Zengwun estuary. In contrast, 120 blackfaced spoonbills stayed in Budai-Beimen wetlands, with the birds resting in Budai Salt Pan Wetland at night, foraging in the harvested fishponds nearby at dawn and in the morning and evening, and flying off temporarily to sandbars in Bazhang estuary when disturbed. Because humans and dogs disturbed them, $21.7 \% \pm 9.8 \%$ of the black-faced spoonbills had to forage in the estuary to get sufficient food. On 27 April, we observed that the birds' daytime foraging was disturbed so frequently that they had to move constantly between sandbars and harvested fishponds and even forage in the estuary occasionally. On 3 May, a few spoonbills came to the shoal in Bazhang estuary in the morning but were unable to forage sufficiently, and being increasingly disturbed in the afternoon, they left in the evening to forage in the fishponds.

\subsection{Fish in Bazhang Estuary}

Between April and June 2013, in total 674 fish and shrimp specimens, belonging to 25 species from 13 families, were collected in the black-faced spoonbill habitats of Bazhang estuary. The most abundant species was the tilapia (Cichlidae, 42.4\%), followed by greasyback shrimp (Metapenaeus ensis, 23.9\%), greenback mullet (Chelon subviridis, 9.9\%), eastern keelback mullet (C. affinis, 4.8\%), and large-scale mullet (C. macrolepis, 2.8\%). These species accounted for more than $86.2 \%$ of all the fish and shrimp collected in Bazhang estuary.

Tilapia was the most abundant species of fish in our samples, and it was also the most abundant species at our SBSP sampling site. Other species such as C. affinis, C. macrolepis, and C. subviridis were distributed more evenly in coastal wetlands, and these were all food sources of the black-faced spoonbills.

\subsection{Analysis of Satellite Imagery}

By analyzing the satellite images, we noted the major changes in Zengwun estuary terrain from 2007 to 2012 (Figures 5 and 6). In the region we analyzed (1744.6 ha), the result of the classification of water depth was as

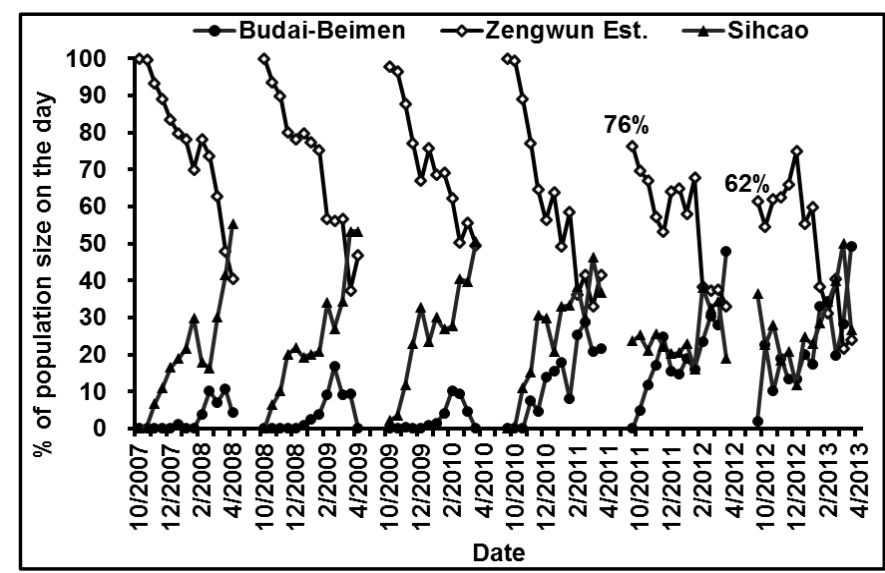

Figure 4. Population size of black-faced spoonbills in the Southern Taiwan from October 2007 to April 2013. 


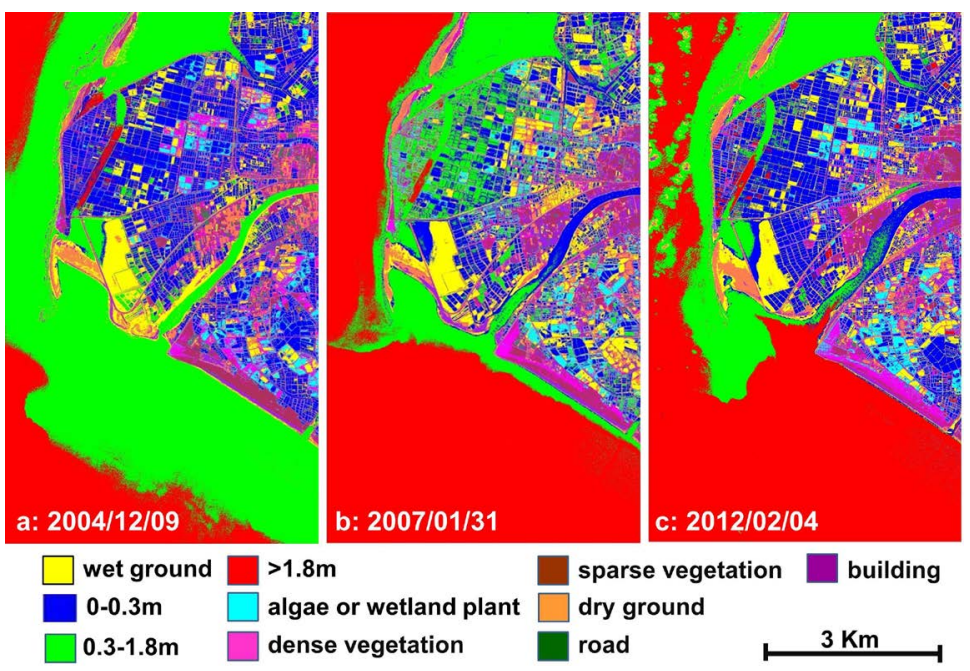

Figure 5. Comparison of three high tide satellite images from 2004 to 2012. Red indicates the water depth more than $1.8 \mathrm{~m}$, light green for $0.3-1.8 \mathrm{~m}$, blue for $0-0.3 \mathrm{~m}$, and yellow for wet ground.

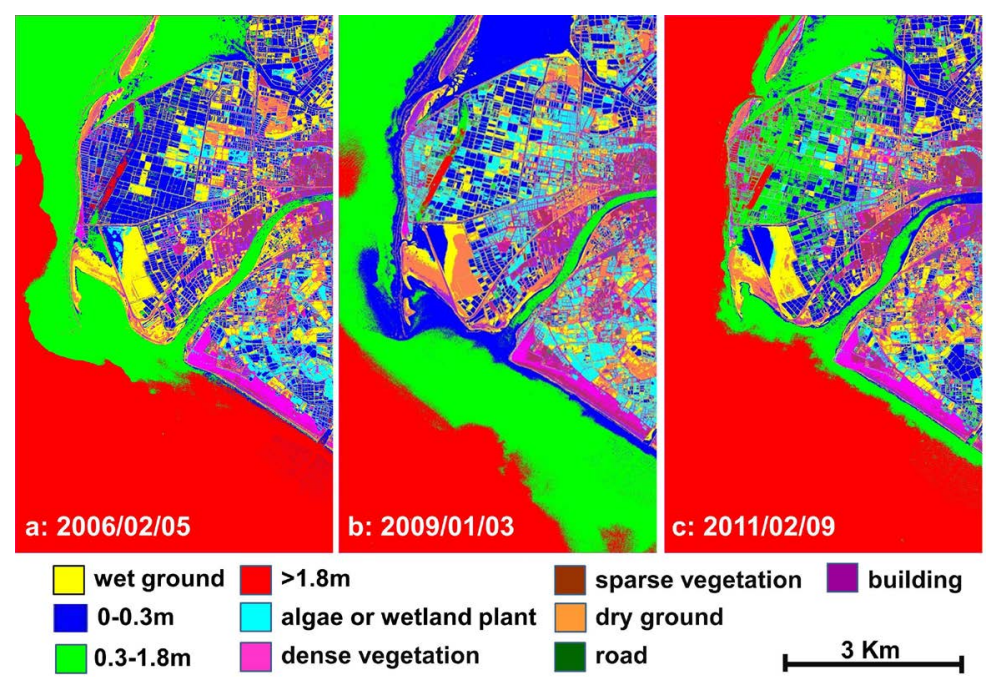

Figure 6. Comparison of three low tide images from 2004 to 2012. Red stands for the water depth more than $1.8 \mathrm{~m}$, light green for $0.3-1.8 \mathrm{~m}$, blue for 0 $0.3 \mathrm{~m}$, and yellow for wet ground.

follows: $0.3-1.8 \mathrm{~m}, 30.2 \% \pm 8.6 \%$; $0-0.3 \mathrm{~m}, 19.5 \% \pm 6.1 \%$; and wet ground, $16.8 \% \pm 5.6 \%$. The terrain changed greatly between years from these satellite images as shown in Figures 5 and 6 . From these figures, we also found that because of the loss of sand source, the area of water deeper than $1.8 \mathrm{~m}$ in the intertidal zone increased greatly (red color area in Figures 5 and 6), and caused the habitats of crabs and the area where the fishermen could catch glass eels vanished gradually. From 2007 to 2012 at BFSR, the terrain of BFSR site also changed greatly, and the result of the classification of water depth was as follows: $0.3-1.8 \mathrm{~m}, 5.8 \% \pm 8.8 \%$; 0 $0.3 \mathrm{~m}, 23.3 \% \pm 7.3 \%$; and wet ground, $49.7 \% \pm 20.7 \%$. In 2009 , the areas of regions suitable for black-faced spoonbills, wet ground decreased slightly (Figures 5-7). BFSR, located in the inner side of seawall, was a silted intertidal, and because of the floodgates around it opened too wide since 2009, the water depth of BFSR became deeper and this water depth last longer than before. This made the habitat worse for the black-faced spoonbills to rest, and the staying time for the black-faced spoonbills became shorter.

From 2007 to 2012 at MWH, the result of the classification of water depth was as follows: wet ground, 17.5\% $\pm 4.7 \%$; dry ground, $12.5 \% \pm 4.6 \%$; and places with algae or wetland plants, $12.4 \% \pm 4.0 \%$ (Figures 5,6 and 8 ). 


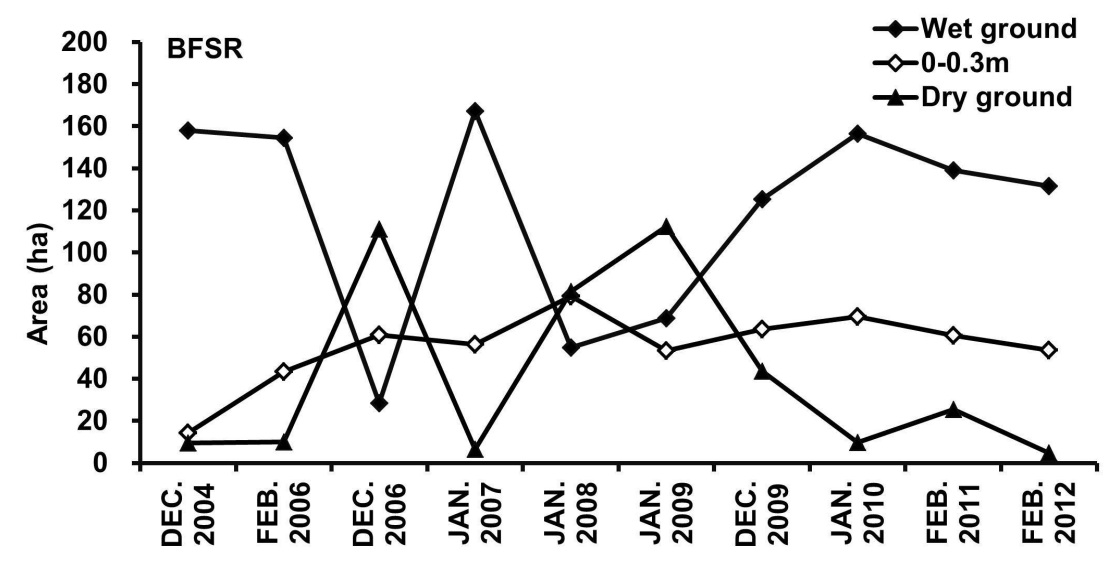

Figure 7. Comparison of the habitat environment change by unsupervised classification in Black-faced Spoonbills Refuge (BFSR) in the north bank of Zengwen estuary from 2004 to 2012.

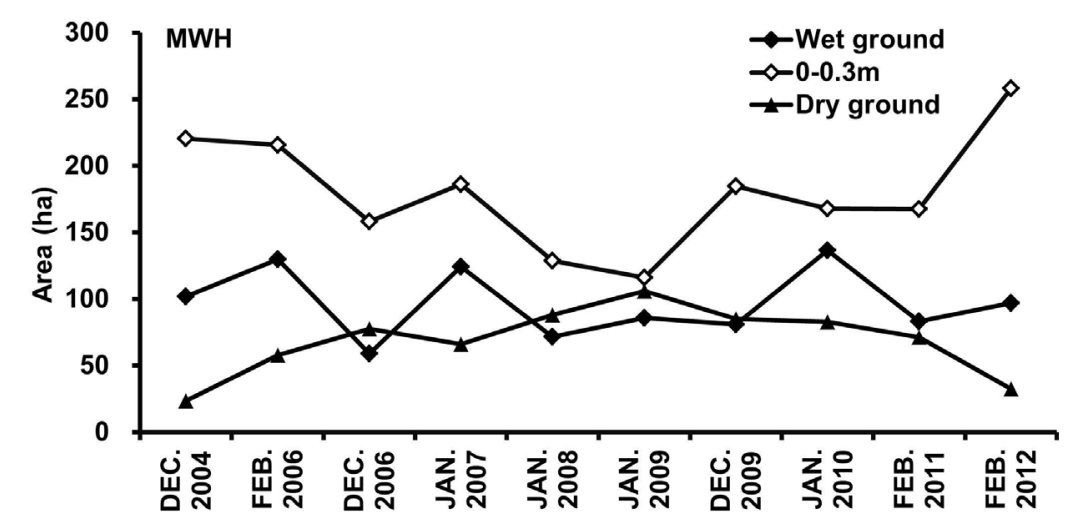

Figure 8. Comparison of the habitat environment change by unsupervised classification in the Major Wildlife Habitat (MWH) in the north bank of Zengwen estuary from 2004 to 2012.

Before February 2010 at MWH, fishermen mainly raised milkfish and clams in their fishponds, and the water depth in the fishponds used being less than $1.8 \mathrm{~m}$. In the harvest period of these fishponds in winter, they provided rich food for the black-faced spoonbills. However, between October 2010 and February 2012, many fishermen deepened their fishponds at MWH to deeper than $1.8 \mathrm{~m}$ to raise grouper fish, and this change made these fishponds could not be the food source for the black-faced spoonbills. The area occupied by deep-water fishponds in February 2012 was twice that in February 2011, and the area of drying pools with shallow water decreased by 41.3\% (Figures 5, 6 and 8). Thus, the food source and resting area available for black-faced spoonbills diminished. Moreover, in February 2012, the areas of dry ground and places with algae or wetland plants decreased to just $58.8 \%$ and $47.2 \%$ of their averages, respectively. The change of the fishponds at MWH reduced the area suitable for black-faced spoonbills, which could be why the spoonbills leaved for other habitats.

In September 2012 and April 2013, the area of habitats, which were suitable for black-faced spoonbill's foraging (water 0 - $0.3 \mathrm{~m}$ deep) in Budai Salt Pan Wetland, measured 663.5 ha (56.6\%) and 587.0 ha (50.1\%), respectively, which accounting for the majority of the area in the Budai Salt Pan Wetland, followed by places with water 0.3 - $1.8 \mathrm{~m}$ deep (Figure 9).

This presence of ample land area with water depth suitable for foraging may be one of the reasons why some of the black-faced spoonbills stay here when they first arrive in Taiwan in autumn (Figure 4). In the winter census of 2012-13, the SBSP site had the maximal foraging and rest area for black-faced spoonbills; at this site, the area of places with water deeper than $1.8 \mathrm{~m}$ fell from 106.7 ha (27.6\%) to 1.2 ha $(0.3 \%)$, and the area of places with water less than $1.8 \mathrm{~m}$ deep increased from 233.8 ha (60.5\%) to 306.8 ha (79.4\%). 


\section{a: $2012 / 9 / 21$}
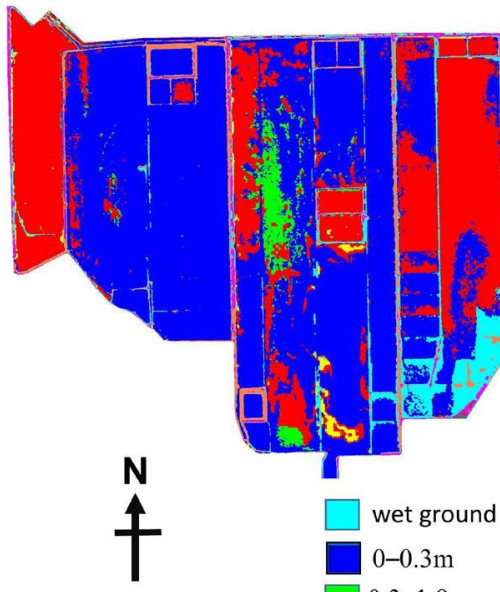

$$
\begin{aligned}
& \square \text { wet ground } \\
& \square \quad 0-0.3 \mathrm{~m} \\
& \square \quad 0.3-1.8 \mathrm{~m}
\end{aligned}
$$

$1 \mathrm{~km}$

\section{b: $2013 / 4 / 29$}

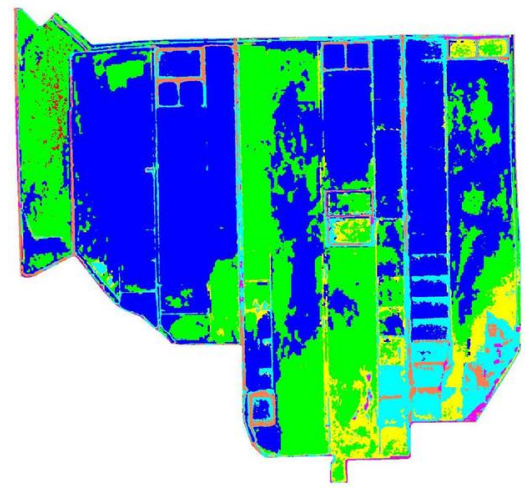

dense vegetation

mid-dense vegetation

sparse vegetation

dry ground or road

dry sand or building

Figure 9. Comparison of two South Budai Salt Pan images in 2012 and 2013. Red refers to the water depth more than $1.8 \mathrm{~m}$, light green for $0.3-1.8 \mathrm{~m}$, blue for 0 $0.3 \mathrm{~m}$, and yellow for wet ground.

\section{Discussion}

In January 2013, Hong Kong Bird Watching Society reported that 1628 black-faced spoonbills were in Taiwan, of which only 138 (8.5\%) stayed in BFSR, a record low whose seriousness cannot be underestimated [9]. According to our records, many of the spoonbills moved to the wetlands of Budai-Beimen and used them as new habitats. Budai Salt Pan is a closed wetland, and when the water vaporized in winter, the wet ground and shallow water area would increase. This made foraging and resting easier for black-faced spoonbills, whose numbers at this site increased annually.

Conversely, because the wintering population of black-faced spoonbills at Sihcao wetlands has been increasing, new protection areas in Southwestern Taiwan must be established to ensure continued growth in spoonbill number. Furthermore, sufficient quantities of fish must be maintained in the existing reserves and the adjacent fishponds, which were all leased from the government, to protect this endangered wader [8].

When fishponds were deepened to raise groupers and young milkfish, the black-faced spoonbills could no longer use the fishponds in winter [19]. Because their food availability was likely insufficient and their rest area existed more disturbance, black-faced spoonbills moved to adjacent estuaries and wetlands such as Budai Salt Pan, which also offered greater shallow-water area and less artificial disturbance than BFSR in Zengwun estuary.

\section{Conclusions}

Since1991, the number of black-faced spoonbill in the world increases yearly, and nearly half of them come to Taiwan every year [7]-[9]. The necessity of more new habitats and improving food availability at existing habitats became apparent when the number of wintering bird increased [17] [27]. On the other hand, between December 2002 and January 2003, there was 73 spoonbills died of type C1 toxin of Clostridium botulism, which were caused by that when the fisherman put too much feed into the fishpond, the uneaten feed sank in the bottom of the fishpond, and it built an anaerobic environment loved by the C1 toxin [17]. When the black-faced spoonbills foraged in the fishponds, the C1 toxin was disturbed to rise up, and eaten by the black-faced spoonbills. Thus, additional protected areas or reserves must be established along the southwestern coast of Taiwan to reduce the risk of avian diseases.

According to the population distribution of black-faced spoonbills in the last 2 wintering seasons, there were about 35\% - 50\% of the spoonbill inhabited Aogu Wetland and Budai Salt Pan consistently, and took refuge in Bazhang estuary when disturbed (Figure 4). Our inference is that because of the change of raised fish in the 
fishponds and the change of environment, the black-faced spoonbills clearly did not have sufficient food in the wetlands of Zengwun estuary. There were 5000 ha of abandoned salt-pans, which all ruled by the government, along the southwestern coast of Taiwan. The abandoned salt-pans had floodgates and ditches to have their water depth to be controlled $<30 \mathrm{~cm}$, suitable for the spoonbills to rest; thus, together with the harvested fishponds there, they build up a good habitat for the spoonbills to rest and forage. We had presented a proposal to ask the government to establish a series of protected areas or reserves along the southwestern coast of Taiwan (under the auspices of Planning of the Southwest Coast National Scenic Area, and Coastal Reserve Plans). These newly proposed protection areas would encompass 10 wetland reserves and 7 estuary reserves (totaling $3400 \mathrm{ha}$ ) including BFSR and Shihchu Wildlife Reserve (Figure 1). In addition, however, a detailed plan must be implemented urgently to construct an ecological corridor, which was composed of estuaries, lagoons, marshes, fishponds, and abandoned salt pans, to support sufficient food sources and safe resting habitats along the southwestern coast of Taiwan.

\section{Acknowledgements}

We thank the Wild Bird Society of Tainan, and Mr. Philip T.-H. Kuo and Mr. Po-Ling Deng for conducting field investigations on black-faced spoonbills. We also thank Dr. Yih-Tsong Ueng for providing the ecological information of black-faced spoonbills and Mr. Ming-Jhih Chen for examining fish in the laboratory.

\section{References}

[1] Stillman, R.A., West, A.D., Caldow, R.W.G. and dit Durell, S.E.A.Lev. (2007) Predicting the Effect of Disturbance on Coastal Birds. Ibis, 149, 73-81. http://dx.doi.org/10.1111/j.1474-919X.2007.00649.x

[2] Hu, J., Hu, H. and Jiang, Z. (2010) The Impacts of Climate Change on the Wintering Distribution of an Endangered Migratory Bird. Oecologia, 164, 555-565. http://dx.doi.org/10.1007/s00442-010-1732-z

[3] Kociolek, A.V., Clevenger, A.P., St. Clair, C.C. and Proppe, D.S. (2011) Effects of Road Networks on Bird Populations. Conservation Biology, 25, 241-249.

[4] Wood, C., Tomida, H., Kim, J., Lee, K., Cho, H., Nishida, S., Ibrahim, J., Hur, W., Kim, H., Kim, S., Koike, H., Fujita, G., Higuchi, H. and Yahara, T. (2013) New Perspectives on Habitat Selection by the Black-faced Spoonbill Platalea minor Based upon Satellite Telemetry. Bird Conservation International, 23, 495-501.

[5] Ueta, M., Melville, D.S., Wang, Y., Ozaki, K., Kanai, Y., Leader, P.J., Wang, C.-C. and Kuo, C.-Y. (2002) Discovery of the Breeding Sites and Migration Routes of Black-faced Spoonbills Platalea minor. Ibis, 142, 340-344. http://dx.doi.org/10.1046/j.1474-919X.2002.00037.x

[6] Nguyen, D.T. (2004) Conservation Status of Black-faced Spoonbill in Vietnam. Pages 184-191 in International Symposium for the Conservation of Black-faced Spoonbills in East Asia. Korean Federation for Environmental Movement Press, Seoul.

[7] Lee, W.-H. and Liu, K.-Y. (2004) Age Structure of Wintering Black-faced Spoonbills in Hong Kong 1998/99-2003/04. Pages 128-136 in 2004 International Symposium for the Conservation of Black-faced Spoonbills in East Asia. Korean Federation for Environmental Movement Press, Seoul.

[8] Ueng, Y.-T., Wang, J.-P. and Hou, L.P.-C. (2007) Predicting Population Trends of the Black-faced Spoonbill (Platalea minor). The Wilson Journal of Ornithology, 119, 246-252. http://dx.doi.org/10.1676/05-112.1

[9] The Hong Kong Bird Watching Society. (2013) 2013 Black-faced Spoonbill Results of Synchronized Global Census.

[10] The Hong Kong Bird Watching Society. (2011) 2011 Black-faced Spoonbill Results of Synchronized Global Census.

[11] Chang, J.-C., Shih, T.-T. and Chen, H.-L. (1996) A Study on Geomorphological Change of Tainan Coastal Plain, Southwestern Taiwan, Geographical Research, 26, 19-56.

[12] Kuo, S.-R., Lin, H.-J. and Shao, K.-T. (2001) Seasonal Changes in Abundance and Composition of the Fish Assemblage in Chiku Lagoon Southwestern Taiwan. Bulletin of Marine Science, 68, 85-99.

[13] Chen, H.-L. and Chang, J.-C. (2003) The Effect of Tsengwen Reservoir on River Discharge and Sediment Load. Geographical Research, 39, 37-53.

[14] Yu, S.-M. (2009) Coastal Wetland Monitoring and Evaluation with Multitemporal Remote Sensing Images. Master thesis, University of Kun Shan, Tainan, Taiwan, 154.

[15] Kondolf, G.M. (1997) Hungry Water: Effects of Dams and Gravel Mining on River Channels. Environmental Management, 21, 533-551. http://dx.doi.org/10.1007/s002679900048

[16] Abam, T.K.S. (1999) Impact of Dams on the Hydrology of the Niger Delta. Bulletin of Engineering Geology and the 
Environment, 57, 239-251. http://dx.doi.org/10.1007/s100640050041

[17] Ueng, Y.-T., Perng, J.-J., Wang, J.-P., Weng, J.-H. and Hou, L.P.-C. (2007b) Diet of the Black-faced Spoonbill Wintering at Chiku Wetland in Southwestern Taiwan. Waterbirds, 30, 85-91. http://dx.doi.org/10.1675/1524-4695(2007)030[0086:DOTBSW]2.0.CO;2

[18] Chu, W.-S., Hou, Y.-Y. Ueng, Y.-T. and Wang, J.-P. (2012) Length-Weight Relationship of Largescale Mullet, Liza macrolepis (Smith, 1846), off the Southwestern Coast of Taiwan. African Journal of Biotechnology, 11, 1948-1952.

[19] Huang, S.-Y., Wang, H.-C., Tsai, W.-K. and Hsueh, M.-L. (2013) Utilization of Fish Farm by Waterbirds during the Process of Drying Pondcase Study of Hard Clam and Milkfish Pond in Chiku. In: Hsueh, M.-L. Ed., The 4th Taiwan Wetland Ecosystem Seminar, Taichung, Taiwan, 122-128

[20] Yang, J.Y.-C. and Ueng, Y.-T. (2011) Taiwan’s Wetlands of Importance. Urban and Rural Development Branch, Construction and Planning Agency, Ministry of the Interior, Taipei, Taiwan, 192.

[21] Lee. P., Sheu, J. and Tsai, B. (1995) Wintering Habitat Characteristics of Black-faced Spoonbill (Platalea minor) at Chi-Ku, Taiwan. Acta Zoologica Taiwanica, 6, 67-78.

[22] Burton, N.H.K. (2007) Landscape Approaches to Studying the Effects of Disturbance on Waterbirds. Ibis, 149, 95-101. http://dx.doi.org/10.1111/j.1474-919X.2007.00658.x

[23] Fan, X.-Z. and Zhang, L. (2012) Spatiotemporal Dynamics of Ecological Variation of Waterbird Habitats in Dongtan area of Chongming Island. Chinese Journal of Oceanology and Limnology, 30, 485-496. http://dx.doi.org/10.1007/s00343-012-1149-0

[24] Chen, M.-J. (2012) The Composition of Fry and Engraulid Breeding Season in the Chiku Wetland of Taiwan. Master Thesis, University of Kun Shan, Tainan, Taiwan, 57.

[25] Oshima, M. (1922) A Review of the Fishes of the Family Mugilidae Found in the Waters of Formosa. Annals of Carnegie Museum, 13, 240-259.

[26] Shen, S.-C. (Chief Editor). (1993) Fishes of Taiwan. Department of Zoology, National Taiwan University Press, Taipei, Taiwan.

[27] Liang, S.-H., Shieh, B.-S. and Fu, Y.-S. (2002) A Structural Equation Model for Physiochemical Variables of Water, Benthic Invertebrates, and Feeding Activity of Waterbirds in Sitsao Wetlands of Southern Taiwan. Zoological Studies, 41, 441-451. 